Revista Aspas

ppgac - USP

Artigo

\title{
EMPEDRAMENTO CORPORIFICADO: REFLEXÃO ACERCA DO PROCESSO URBANO DE IMUNIZAÇÃO A PARTIR DA RELAÇÃO ENTRE CORPO E PEDRA
}

EMBODIED STONEWORK: REFLECTION ON THE URBAN IMMUNIZATION PROCESS FROM THE RELATIONSHIP BETWEEN BODY AND STONE

CANTERÍA INCORPORADA: REFLEXIÓN SOBRE EL PROCESO URBANO DE INMUNIZACIÓN A PARTIR DE LA RELACIÓN ENTRE CUERPO Y PIEDRA

Maeza de Vasconcelos Donnianni

Maeza de Vasconcelos Donnianni Unespar; Mestranda; Pesquisa em andamento. Área de estudo: Artes. Orientador: Prof. Dr. Giancarlo Martins. Atuação profissional no campo da dança e perfomance.

E-mail:maeza.donnianni@gmail.com 


\section{Resumo}

A discussão é dedicada a refletir sobre como são moldadas as relações na multidão contemporânea, ressaltando os modos de atuação do biopoder na urbanidade, que objetivam a imunização da comunidade. Para tanto, relacionamos os modos como a pedra e o corpo na cidade, são ordenados de maneiras semelhantes no sistema. Em um jogo de corpo que empedra e pedra que move, a propomos um olhar para os desvios, os tropeços como possibilidade de ruptura dessa lógica opressora da potência de vida.

Palavras-chave: cidade, comnunidade, contrapoder, imunidade, multidão.

\section{Abstract}

The discussion is dedicated to reflecting on how relationships are shaped in the contemporary crowd, emphasizing the ways of acting biopower in urbanity, which aim at immunization of the community. To this end, we relate the ways in which the stone and the body in the city are ordered in similar ways in the system. In a game of body that emstone and stone that moves, we propose a look at the deviations, the stumbles as a possibility of rupture of this oppressive logic of the power of life.

Keywords: city, community, counterpower, immunity, crowd.

\section{Resumen}

La discusión está dedicada a reflexionar sobre cómo se forman las relaciones en la multitud contemporánea, enfatizando las formas de actuar biopoder en la urbanidad, que tienen como objetivo la inmunización de la comunidad. Con este fin, relacionamos las formas en que la piedra y el cuerpo en la ciudad se ordenan de manera similar en el sistema. En un juego de cuerpo que emstone y piedra que se mueve, proponemos una mirada a las desviaciones, los tropiezos como posibilidad de ruptura de esta lógica opresiva del poder de la vida.

Palabras clave: ciudad, comunidad, contrapoder, inmunidad, multitud 
Brita, mármore, são tomé, ardósia, granito, basalto, miracema, seixo ralado, mosaico português, pedra seca ou com rejunte, concreto, placas drenantes, calcário, basalto, pedras goianas, gnaisse, quartzito, seixo natural, pedra de rio, brita branca, pedra dolomita, argila expandida, laterita, areia de construção, argonita, turmalina, turquesa, topázio, tanzanita, safira, rutilo, rubi, perídoto, pedra do sol, pedra da lua, opala, malaquita, jade, granada, euclásio, esmeralda, diamante, ciprino, âmbar, ametista, azurita. PEDRAS. Interior, exterior. Chão, muro, parede, pia, bancada, vaso. Jardim, aquário, joia, decoração. Características específicas para espaços específicos. Agrupadas por seus aspectos em comum, deslocadas do mundo comum. Justapostas, porém fadadas ao desencontro.

Para que não se risquem, se deformem, desgastem, se encontrem. Para que sejam autoconstrução em muros altos. Longe do estar com o comum, perto das que possuem em comum. Longe de ser simples pedra, ou seja, longe de ser a instabilidade inerente à vida, distante de ser relação. Resumida a ser coisa. Muro. Jardim. Chão. Parede. Aquário. Poste. Anel. Calçada. Distante de ser o vazio, a transitoriedade do verbo "estar", para se ver contida na flexão "é" do verbo "ser".

São carregadas de um lugar ao outro. Sem opção de escolha. Levadas no bolso, num saco, em uma caçamba ou carrinho de mão. Agrupadas em um amontoamento de mais das mesmas. Empilhadas e agrupadas entre as parecidas. Conformadas a estar em tal espaço. Impossibilitadas de estar em outro. Porque foi dito como obviedade que a composição que lhe é própria, do verbo possuir, é finita em concretude louvável. Porque o deslocamento condicionado parece e aparece como opção única.

Vejo braços, pernas, cabeças, e passos. Pouco ou bastante petrificados, e pedra que sou, me reconheço nos milhares de vultos que passeiam em correntes de congestionamento no empedramento da carne. Petrificação, oposta aos empedramentos de uma rocha, que desprendida da montanha, se põe a rolar por aí. Petrificação do tipo lapidada, por e para, uma rede de asfixia do fluxo natural de ser pedra. Pedra que sou, vivo em cima do muro, bem como em toda a extensão deste, e vivendo uma temporalidade 
distinta dos tantos corpos que trafegam minhas redondezas, os vejo petrificar em infinitas ruínas, miúdas o suficiente para passarem despercebidas.

Olho como gente que sou para essas linhas todas que de volta me olham. A frieza geométrica que desliza como pincel desenhando as trilhas que miro, quase não combina com a temperatura que assa a planta do meu pé descalço no asfalto. Movendo-me, sinto o abafado do vento artificial deslocado pelo motor muito próximo da nuca durante minha travessia. A calçada me salva, como se fosse capaz de abrigar meu corpo. Delimitado como moldura. Recortes e traços. De pedra. Meio-fio, as bordas daquela rotatória, cruzando a BR 116 pelo viaduto que repousa no ar denso e turvo, subindo construções pelas paredes e o cheiro de cimento molhado toda vez que a água tenta varrer a rigidez.

Sinto. Porém nem sempre, e muitas vezes nunca. Há algo de familiar em cada uma dessas trilhas de pedra que me cercam o corpo, porém me percebo viva demais para parar. Para parar para pensar, para parar para pensar em pedras e pessoas, e tão improvável quanto, é encontrar sentido em colocá-las no mesmo assunto.

Contudo, observa-se que é na imersão da urbanidade que grande parte da população humana se desenha nas relações atualmente, que é onde estamos constantemente nos construindo pela troca com o outro, em atravessamentos multidirecionais. Logo, observar os modos de organização dessa urbe pode ser interessante, no tocante a uma melhor compreensão dos propulsores desses corpos que movem a contemporaneidade. Portanto, olhar para a dita "selva de pedra", é encontrar o entrelaçamento entre as vivências de gente e de pedra em uma perspectiva de coexistência, é o reconhecimento de um corpo-pedra, ou seja, um corpo-cidade.

Ao contrário do que por alguns séculos, se manteve como verdade no sustento da ideia de indivíduos - ressaltamos essa individualidade aqui, como concretude atrelada a uma consistência substancial fixa relacionada a um conjunto - como processos prontos a priori, hoje percebemos essa questão de outro modo. Estamos a todo o momento inacabados uns nos outros, delineando nossas singularidades na relação com o outro, de modo que a busca por uma suposta completude, seja em si, a negação do próprio corpo 
vivente, o qual veste a vulnerabilidade que the permite a constante desterritorialização e reconstrução de si mesmo, bem como a de nossos territórios. Porém, apesar do reconhecimento da nossa existência como intrinsecamente relacional, muitas vezes o que notamos é a:

\begin{abstract}
anestesia da vulnerabilidade ao outro - anestesia tanto mais nefasta quando este outro é representado como hierarquicamente inferior na cartografia estabelecida, por sua condição econômica, social, racial ou outra qualquer. É que a vulnerabilidade é condição para que o outro deixe de ser simples objeto de projeção de imagens pré-estabelecidas e possa se tornar uma presença viva, com a qual construímos nossos territórios de existência e os contornos cambiantes de nossa subjetividade (ROLNIK, 2006, p.2).
\end{abstract}

O que observamos é exatamente o quadro posto pela pesquisadora brasileira, atuante nos campos da cultura, da arte e da psicanálise, Suely Rolnik. Caminhamos em linhas retas e passos largos, com foco em uma linha de um horizonte delineada por pedras erguidas. Sem tropeços, tampouco hesitação, seguimos nutrindo o abarrotamento sensorial de nossos corpos, nos lapidando constantemente, para um estado de imunização às diferenças. Deslocamo-nos em uma grande marcha compressora das irregularidades dos chãos sob nossos pés. Livramo-nos de tudo ao redor, e de todos que passam lado a lado também. Separados e ordenados por muros, paredes, viadutos, e assim como as pedras, avaliados por nossa funcionalidade dentro do sistema que alimentamos.

Entretanto, retomando que conforme dito anteriormente nossa existência no mundo é inextricável às relações, se o ser estando no mundo é o sujeito que impreterivelmente tem a comunidade como ponto de partida, de que forma tem se concebido esse modo de se relacionar que se nega aos vínculos? Se necessitamos nos lançar uns aos outros como premissa da própria vida, se é o confronto na heterogeneidade que nos faz estar aqui nesse momento em prosa, como é possível que a aquietação dos encontros seja naturalizada como elemento constituinte de alguma forma de vida?

Para iniciar o esmiuçamento dessa questão, olhemos um pouco mais atenciosamente para o entendimento de comunidade em si e a perspectiva na qual a mesma é contextualizada aqui. Primeiramente há de se ter nítido que a ideia tradicional de comunidade como um conjunto de indivíduos, que na 
própria inteireza se configura como uma fusão, um todo dotado de plenitude, não é a que nos interessa refletir. Pelo contrário, aqui pensaremos sob uma perspectiva dessubstancialista, na qual a comunidade seria uma integração coletiva de sujeitos na qual o único ponto comum seria a condição de serem singulares.

Trazendo as proposições do filósofo italiano, Roberto Esposito (2007) acerca do assunto, entendemos a comunidade (communitas) partindo da origem etimológica no dicionário latino, como união do "cum" e "munus". A comunidade estaria, portanto, condicionada à experiência da relação com o outro (cum), o ser-com, o próprio ser como o "entre", como relação. Integrado à imprescindibilidade de doação, como uma dívida infindável com o outro (munus), e resultando assim na desintegração do sujeito enquanto substância, expropriando-o na morte subjetiva de si, na manifestação do seu cerne essencialmente vazio por ser encontro. Há então, a obrigatoriedade de compartilhamento desse estar em dívida com o outro, o qual não é outro sujeito completo e sim esse processo de alteridade nunca completo.

Essa lógica constituinte da sociedade atual, não esteve por todos os tempos deste modo arquitetada. Sabe-se que foi por volta da década de 1970, em grande parte do mundo e por volta de duas ou três décadas mais tarde no Brasil, que se iniciou um movimento no sentido da fragmentação do até então regime disciplinar fordista em vigência, bem como, da política de subjetividade individualista, fazendo emergir a multidão contemporânea com suas características ambivalências, em detrimento do povo, compreendido como, invariavelmente, convergido em um Uno constituído pelo Estado.

Multidão, conforme o proposto pelo filosófo e semiólogo italiano Paolo Virno (2013), em diálogo com Marx e Simondon, é o conjunto de "indivíduos sociais", é uma rede tecida por inúmeras singularidades de indivíduos, a pluralidade de ser dos "muitos". Porém, diferentemente do que se constitui no povo, as singularidades não são premissas e sim, são o destino resultante de um processo de individuação, do qual resulta a complexificação do Uno ao "muitos", ou seja, o ser social. Como precedente para a frutificação da singularidade, há o pré-individual (aparato motor, órgãos sensoriais, prestações perceptivas não passíveis de individuação, e a língua histórico- 
cultural) que dá forma a singularidade, sem que nunca haja a individuação completa.

A multidão pós-fordista é instabilidade e contínua indeterminação, sendo a pluralidade de sujeitos viventes em plena crise, pela ebulição do conflito na coexistência da porção pré-individual $e$ individuada, progressivamente refinada pela experiência coletiva. A sensação de insegurança na iminência ininterrupta do medo angustiante, medo este inerente à própria existência com o indeterminado, é o mais expressivo ponto de comunhão, característico da multidão, o sentimento de "não se sentir em sua própria casa" (VIRNO, 2013, p.18), de estranheza pelo risco generalizado de estar no mundo.

O medo, embora seja intrínseco à experiência coletiva de vida dos "muitos", os quais constituem essa comunidade dos diferentes, acaba induzindo a elaboração de diversas formas proteção ao desconhecido, à sensação de incerteza indissociável da vida. Seja no levantamento de uma cerca de pedras, no corte afiado de uma lâmina, no deslocar enlatado sobre rodas, ou no grito disparado por alarmes, estamos sempre buscando a paz de sentir a proteção na própria constatação do perigo. O medo que une, que encontra os tantos "muitos" na multidão, é o mesmo que imuniza.

Por conseguinte, o mesmo medo que aparece no despertar da nossa potência coletiva, é o que aponta para um alastramento de inúmeras formas de negação aos afetos, como um vírus altamente transmissível que vai apagando a vida pouco a pouco. É a imunidade pela contaminação desse medo que passa de corpo em corpo, pele em pele, boca a boca, em olho por dente. Transmissão na contaminação se exibindo ousada e despudoradamente como dispositivo de estabilidade da dinâmica da urbe. A transmissão do medo como artéria comum à urbanidade contemporânea, mantém pulsante os jogos de poder, política e dinheiro em um escoamento hemorrágico de alcance pelos chãos tantos, que de gota a gota, faz patinar nossa potência de vida.

A partir dessa explanação, voltemos à questão primeiramente projetada. Se a comunidade é primordial para a nossa existência, por que estamos sob a condição de imunes ao que é comum, por uma 
invulnerabilidade aos afetamentos, sendo privados da experiência da alteridade, incapazes de nos vincularmos, e jogados numa massa homogênea, invisíveis em numerosos achatamentos? Sobrevivemos com naturalidade à petrificação forçada. Somos polidos, categorizados e distribuídos pelo espaço da cidade consentindo com um abrandamento da vida que violentamente nos é imposto.

A anestesia do nosso corpo vai totalmente ao encontro dessa política individualista, pois é apenas na recusa do encontro das singularidades que há a possibilidade de nos mantermos em nossas supostas identidades fixas, de modo que essa lógica instaurada na sociedade só se firme na intensificação da imunização. Estabelece-se assim, uma relação de simetria entre comunidade e imunidade. Se a comunidade é a comunhão do nada, do vazio, é a pedrinha soprada pelos ventos tocando com o corpo mundos a fora, a imunidade é, por conseguinte, a busca de um aquário ou um vaso para repousar na paz da homogeneidade, é o roubo da ausência compartilhada, o perdão da dívida experiencial.

A comunidade que em sua potência desdobra-se para si e em si, não interessa para o funcionamento do sistema capitalista pós-moderno tanto política como economicamente, portanto, o mesmo considera a vida como algo que deva ser controlado, administrado pela lei. Logo, há um investimento na imunização como forma de proteção negativa da vida, protegendo-a violentamente da desordem, da instabilidade, da diluição do ser substancial provocada pela construção dos vínculos.

Deste modo, a experiência de morte em ser comunidade tem sido, há décadas atacada, como estratégia aliada à manutenção das hierarquias arraigadas em nosso modo de organização da social. A comunidade tem o que o "Estado não pode tolerar, a singularidade qualquer que o recusa sem constituir uma réplica espelhada do próprio Estado na figura de uma formação identitária reconhecível. A singularidade qualquer, que não reivindica uma identidade (...)" (PELBART, 2008, p.9). A sociedade individualista contemporânea teme as potencialidades da vida enquanto ferramenta de destruição do poder, por isso encontra maneiras de controlá-la mantendo-a privatizada e normatizada, e consequentemente, apaziguada. 
Em um ambiente de circulação frenética, acreditamos na posse da liberdade, e mais do que isso, arquitetamos despretensiosamente um castelo de subjetividade e afetos moventes em nosso corpo, capaz de nos convencer de uma suposta autonomia na decisão de cada um de nossos passos. Com a certeza de que somos livres, ainda que ilusoriamente, não há motivos para imaginarmos ruídos que desestabilizem essa correnteza mantida em perfeito autogerenciamento. Dançando essa incansável coreografia territorialmente limitante, são massivamente diminuídas, as possibilidades de criarmos conexões, e como consequência, temos o enrijecimento de nossos trânsitos individuais, e o enfraquecimento do coletivo.

Deste modo, o poder está largamente distribuído em cada uma das instâncias de vida que compõem a sociedade contemporânea, o que se por um lado nos coroa com a declaração autogerenciamento, por outro nos coloca como motor na perversidade de uma retroalimentação das redes de controle que diariamente nos ditam impossibilidades de existir. No afogamento de capturas por todos os lados e em todos os sentidos, indeliberadamente consentidas, é que acatamos com normalidade a condição de sobreviventes blindando nosso corpo em detrimento do empoderamento da vida, que se vê cada vez mais borrada. Assim, vamos prosseguindo em estado de mortificação, pois, conforme bem colocado pelo filósofo húngaro em relação aos estudos da biopolítica:

O biopoder contemporâneo, o poder sobre a vida, faz sobreviventes, cria sobreviventes e produz sobrevida - é a produção da sobrevida. O biopoder contemporâneo teria essa incumbência, de produzir um espaço de sobrevida biológica, reduzir o homem a essa dimensão residual, não humana, vida vegetativa. (PELBART, 2007, p.59)

Portanto, nessa configuração em que o poder se sobrepõe a toda e qualquer fronteira, se estrutura a regulamentação da vida social. O poder a interpenetra "fundo na vida das populações, nos seus corpos, mentes, inteligência, desejo, afetividade, totalidade do espaço, do tempo, da subjetividade" (PELBART, 2009, p.81), fazendo com que a mesma produza e reproduza meios de reorganização, reordenamentos, que despontam de 
dentro e promovem cada indivíduo, por vontade e mérito próprio, à função de integrante imprescindível desse sistema de desgoverno.

$\mathrm{Na}$ fuga da realidade do temível indeterminado, na procura de calmaria, é que acreditamos nas ideias que nos são vendidas como pedaços de paraíso enfeitando o céu da boca. Deslizamos goela abaixo, os dispositivos que nos colocam na roda do consumo frenético. Compramos o mito neoliberal de que o investimento da energia vital é o suficiente para 0 alcance do inalcançável. Compramos. Consumimos. Ou melhor, vendemo-nos. O dispositivo do medo põe em dúvida a força do munus, desafiando as condições de existência do corpo vivente, e instalando um dilema permanente: ceder ao tsunami do medo ao desviar da dívida concernente a estar-com o outro; ou aceitar a própria morte substancial, e no mergulho nesse medo em comum, encontrar a única possibilidade viver.

Havendo maneiras de livramento das mazelas, vendo. Ou melhor, compro. Motivos não há para o desvio. Parede de isolamento, e o blindado do vidro. Alarme, no carro, no casa, no celular, na eletricidade da cerca. Câmera de ré, no portão, na parede, na vaga, no elevador e na cabine de vigilância. Senha do cartão, da porta, da proteção de tela, controle, chave eletrônica, reconhecimento da digital, identificação facial. O vizinho mais próximo está também do lado de dentro, na calçada de dentro da rua de dentro, e a grama dele tão verde quanto a minha. Muro. Moro. Muramos bem, obrigada. Com a paz da liberdade de quem sabe que a tem, porque a cerca nos cerca apenas de chamadas pessoas de bem.

$\mathrm{Na}$ estruturação desses pequenos mundos intencionalmente isolados da experiência de estar-com, de ser o "entre", o privilégio da anestesia "protetora dos perigos do mundo" é acessível a um número reduzido de pessoas, que criteriosamente selecionadas, são reconhecidas como aptas a fazer parte dessa fantasia de um mundo acetinado. Quem está incluído? Será questão de sorte a oportunidade de fazer parte? Ou de berço? O que diferencia os merecedores dos não merecedores de gozar a plenitude da felicidade? Quem fez por merecer, realmente o fez? O que determina quem está aqui ou acolá? 
Comunidade imune. Multidão sob controle por meio da eficiência dos dispositivos. Biopoder e medo. No sobre ou no sob, por uma visão aérea ou escavando as camadas pelos pés, de longe ou nem tanto, de forma geral, o que está posto é isto e não outra coisa: o domínio dos corpos, a administração da vida. Se de perspectivas e ambivalências sobrevivemos até então, me alegra dizer, que essa explanação toda não termina aqui, no próximo ponto final. Com uma tomada de fôlego a mais, é possível abrir os olhos e perceber o toque da cintilância da luz nos mesmos, e na visibilidade translúcida por detrás da trama do tecido, rasgar pelo toque, as vendas que nos faz apáticos.

No reconhecimento uns dos outros, e na fundamental codependência que nos apoia, nos puxa e nos segura nesse terreno de instabilidade dançante, é possível reescrever o chão. Ao tatearmos trajetórias autorais surge um despertar, um resgate da humanidade há tanto soterrada, e nos colocamos como obstáculo na engrenagem que apagou o meu rosto, e o seu, o dele, a daquelas... Partindo da construção de ações coletivas, podemos então retomar a força da comunidade, da multidão contra o poder dominante. É a possibilidade de romper a bolha de autossuficiência alienante, e encontrar nela tensionamentos que contribuam para a reintegração de posse da nossa potência de vida.

Pois trata-se sempre da vida, na sua dimensão de produção e de reprodução, que o poder investe, e que no entanto, é o caldo a partir do qual emergem os contra-poderes, as resistências, as linhas de fuga. Daí a presença insistente do prefixo bionesse leque conceitual. Biopoder como regime geral de dominação da vida, biopolítica como uma forma de denominação da vida que pode também significar, no seu avesso uma resistência ativa, e biopotência como potência de vida da multidão (...) (PELBART, 2009, p.86)

Recriemos nosso espaço, nosso corpo. Que possamos desordenar nossas pedras e olhar para as especificidades constituintes das mesmas. Que tenhamos pressa de parar, e observar a pausa da pedra desgarrada no meio da rua, pedra essa que ontem era elemento integrante da calçada de um relevo plano, e se colocou a saltar para fora de onde a aprisionaram. Inauguremos um diálogo com essa pedra que ousa interromper o fluxo e aprendamos a dançar com ela. Faz-se necessário: 
(...) retomar o corpo naquilo que the é mais próprio, na sua dor, no encontro com a exterioridade, na sua condição de corpo afetado pelas forças do mundo e capaz de ser afetado por elas. Seria preciso retomar o corpo na sua afectibilidade, no seu poder de ser afetado e de afetar (PELBART, 2007, p.62).

Dançar a pedra. Dançar com as pedras. Mover como pedra. No espetáculo "Pedra no Caminho (1993)", a coreógrafa Célia Gouvêa, propõe aos bailarinos do Teatro de Dança de São Paulo uma relação interessante para observarmos. Pêndulo, balanço. Vai ao chão, salta em um giro, move a testa no solo, impulsiona, voa, despenca com intenção. Mira e lança de uma mão a outra, de outra a uma, de novo e novamente. Dribla, chuta, desloca, vai ao chão e pausa. Rola lentamente e cai em si. Desperta para o outro. Olha com atenção, com o corpo todo. Move junto com. Joga. Cuida, reposiciona o pé, a perna. Desloca de um jeito outro. Redescobre maneiras variadas de tocar, de sentir, de apoiar, de ser suporte, de trocar as pedras. Toca as mãos. Pausa. Reconstrói, mais uma e outra vez.

A pedra como propulsora de cada um desses movimentos. A pedra desgarrada como interrupção de uma lógica acomodada. A pedra como desvio, como disparadora de um outro modo de ser e estar. A pedra sendo propositora dessa dança, desse corpo atento, de um corpo que decide se fazer presente. Corpo e pedra, pedra e corpo, partilhando arestas sem polimento, e se despindo do medo do indeterminado. É o despetrificar pela pedra. É o desimnunizar pela potência de vida. As pedras dizem sobre nós, e contam a mesma história há tempo demais. Quais escritas estamos dispostos a mover com elas? 
Empedramento corporificado: Reflexão acerca do processo urbano de imunização a partir da relação entre corpo e pedra

\section{Referências bibliográficas}

GOUVÊA, Célia. Pedra no caminho. Disponível em:

<http://acervomuseudadanca.com.br/pedra-no-caminho-1993/> Acesso em 30 de maio, 2020.

PAIVA, Raquel (org). O retorno da comunidade: os novos caminhos do social. Rio de Janeiro: MAUAD, 2007.

PÁL PELBART, Peter. Biopolítica. Sala Preta, São Paulo, n.7, p.57-65, 2007.

Disponível em: https://doi.org/10.11606/issn.2238-3867.v7i0p57-66

Elementos para uma cartografia da grupalidade. In: SAADI, F; GARCIA,

S. (Orgs.). Próximo ato: Questões da Teatralidade Contemporânea. São Paulo: Itaú Cultural, 2008, p. 33-37.

Vida capital. Ensaios de biopolítica. São Paulo: Editora lluminuras, 2009.

ROLNIK, Suely. Geopolítica da Cafetinagem, 2006. Disponível em:

<http://www4.pucsp.br/nucleodesubjetividade/Textos/SUELY/Geopolitica.pdf>. Acesso em 3 de janeiro, 2020.

VIRNO, Paolo. Gramática da multidão: por uma análise das formas de vida contemporâneas. São Paulo: Annablume, 2013. 